\title{
Can we predict orofacial cleft in future pregnancy?
}

\author{
Malova $\mathrm{J}^{1}$, Braxatorisova $\mathrm{T}^{1}$, Luha $\mathrm{J}^{1}$, Totka $\mathrm{A}^{2}$, Bohmer $\mathrm{D}^{1}$ \\ Institute of Medical Biology, Genetics and Clinical Genetics, Faculty of Medicine of the Comenius \\ University Bratislava, Slovakia. Jana.malova@fmed.uniba.sk
}

\begin{abstract}
AIM: The aim of this thesis was not only to define the frequency of all orofacial clefts and their particular types, but also to determine the sex of an embryo or fetus and detect associated developmental and chromosomal abnormalities. Approximately one third of orofacial clefts are a part of chromosomal syndromes.

MATERIALS AND METHODS: Retrospective morphological and cytogenetic study of 43 cases of different types of orofacial clefts between 1992-2014 from miscarriages (spontaneous abortions) and premature births. RESULTS: Associated abnormalities were found in 34 cases. Most of the anomalies were skeletal anomalies (29), NTD (24) and anomalies of the abdominal wall (9). Most associated anomalies were found in the R III group (93.3\%). Eleven of the successfully cultivated cases $(26 \%)$ had a normal karyotype and in 14 of the cases (32\%), numerical or unbalanced structural chromosomal aberrations were found.

CONCLUSION: Our data did not show that isolated clefts were not associated with a higher risk of chromosomal aberrations. Higher percentage of chromosomal aberrations found in isolated clefts in our pool can be explained by the age of the embryos and fetuses - usually between day 43 and week 12 . It is nearly impossible to diagnose some associated congenital defects at such an early age. Thanks to the morphological and cytogenetic analysis of embryos and fetuses with orofacial cleft, it is possible to estimate if not determine the etiologic factor which influenced the miscarriage. Additionally, in the case of birth defects, the prognosis for future pregnancy can be offered, which is important information for gynecologist and clinical geneticist (Tab. 5, Fig. 5, Ref. 31). Text in PDF www.elis.sk. KEY WORDS: cleft lip, cleft lip and palate, cleft palate, associated abnormalities.
\end{abstract}

\section{Introduction}

Orofacial clefts are the most common congenital malformations of the facial region that are formed already during the period of 6th - 8th week of the intrauterine development. In addition, they are the second most common birth defect (BD) (13\% of all BD) (5).

Its prevalence in Caucasian population is $1: 1000$. The incidence in Europe is $1: 600$ to $1: 1000$ in all live births, with the majority of sufferers being boys.

Etiology of orofacial clefts is usually multifactorial, they are caused not only by genetic predisposition but also by teratogenic factors, especially in the second and at the beginning of third month when the fetus is most susceptible $(24,19)$. They can be formed as an individual defect or as a part of monogenic or chromosomal disorders. Nonsyndromic cleft lip with or without cleft palate is the most common orofacial birth defect, exhibiting variable prevalence around the world, often attributed to ethnic and environmental differences (2). Approximately one third of orofacial clefts are a part of chromosomal disorders, where associated abnormalities

${ }^{1}$ Institute of Medical Biology, Genetics and Clinical Genetics, Faculty of Medicine of the Comenius University Bratislava, Bratislava, Slovakia, ${ }^{2}$ IInd Department of Gynecology and Obstetrics, Medical Faculty, Comenius University, Bratislava, Slovakia

Address for correspondence: J. Malová, RND, PhD, Institute of Medical biology, Genetics and Clinical Genetics, Faculty of Medicine of the Comenius University Bratislava, Spitalska 24, SK-813 72 Bratislava, Slovakia. influencing the prognosis and survival of the embryo or fetus are present. The most common are anomalies of the CNS, heart and extremities which are often incompatible with life $(3,28)$. The frequency of chromosomal disorders is higher in embryos and fetuses with cleft lip and palate (CLP) diagnosed prenatally than in live births due to prenatal selection through abortion. Whereas only $37 \%$ of newborns with cleft lip (CL) have malformations of other organs (25), $80 \%$ of fetuses with CLP have other birth defects $(15,23)$.

The goal of this work was to determine the overall frequency of orofacial clefts, frequency of their individual types, sex of the embryo or fetus and presence of associated congenital abnormalities. Determining the karyotype of miscarried embryos and fetuses helps to identify the etiology of cleft disorders which might be important for the prognosis of future pregnancy. It is important to determine whether cleft is a part of a chromosomal disorder or whether it was caused by various factors in order to predict its recurrence in a family. That is the reason why all of these materials were cultivated and cytogenetically investigated.

\section{Materials and methods}

The total of 3,918 samples of miscarried and aborted fetuses (medically indicated abortions) were morphologically and cytogenetically investigated during the period of 1992-2014 at the Institute of Medical Biology, Genetics and Clinical Genetics (Faculty of Medicine, Comenius University, Bratislava, Slovakia). 
401-406

The samples were sent from 1st Department of Gynaecology and Obstetrics Medical Faculty Comenius University Bratislava. II. Gynecology and Obstetrics Clinic Medical Faculty Comenius University Bratislava and 1st Clinic of Gynaecology and Obstetrics Slovak Medical University and University Hospital in Bratislava.

\section{Morphological classification}

The completeness and condition (signs of maceration and contamination) of the samples were analyzed. Fetal age of the gestational sac was determined based on its size and morphological characteristics.

Fetal age of the embryo or fetus was determined based on its size bearing in mind the differentiation of various morphological structures $(13,17,29)$.

Material was deemed complete when it contained the embryo or fetus, placenta, embryonic membranes and umbilical cord, or incomplete when it contained only excisions (of a muscle, placenta and part of the umbilical cord), or fragments of the gestational sac tissues (usually trophoblast).

Classification according to Fujikura et al (7) and improved by Fantel et al (1980) (6) was used. It uses explicit criteria, which are based on the macroscopic investigation of the embryo or fetus.

Found clefts were evaluated according to classification of Kernahan and Stark which was accepted by the Fourth International Congress of Plastic and Reconstructive Surgery in 1967.

Class I (R I): Clefts of the primary palate (cleft lip, CL) - upper lip, alveolar process

Class II (R II): Clefts of primary and secondary palate (cleft lip and palate, CLP)

Class III (R III): Clefts of secondary palate (cleft palate, CP)

Class IV (R IV): Atypical clefts:

- Median cleft lip

- Oblique clefts

- Transverse clefts

- Lower cleft lip, nose and other rare clefts

\section{Cultivation of embryonic tissues}

Cultivation of embryonic tissues was performed through shortterm or long-term cultivation. Both embryonic and extraembryonic tissues (amniotic membrane, chorionic villi, umbilical cord and excision of muscle tissue) were used. Short-term cultivation of trophoblast cells lasted 24-48 hours, long-term cultivation several days up to a couple of weeks, depending on the type of the tissue.

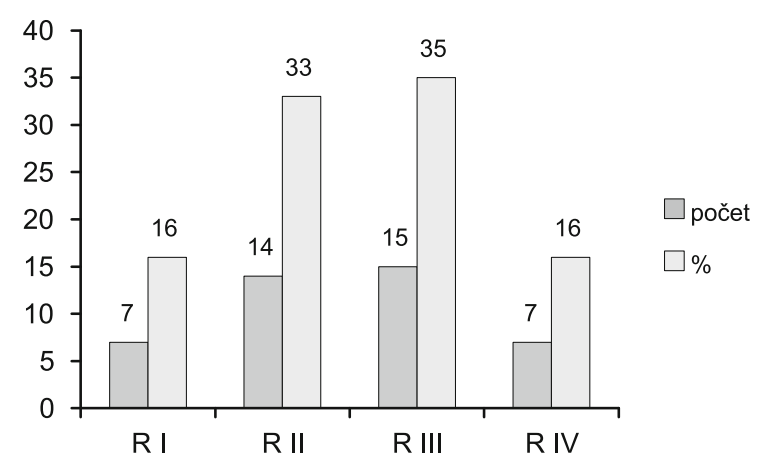

Fig. 1. Percentage of types of orofacial clefts.

Cultivation took place in an open system in humidified atmosphere containing $5 \%$ of $\mathrm{CO}_{2}$ at $37^{\circ} \mathrm{C}$. Cultivation medium was enriched with fetal bovine serum and antibiotic prophylaxis was used. Mitotic poison Colchicin was added for the last two hours of direct short-term cultivation. The same concentration $(0.2 \mathrm{mg} / \mathrm{mL})$ was used for the last six hours of long-term cultivation.

G-banding and conventional chromosome painting were used.

\section{Results}

An amount of 478 of all 3918 samples analyzed were complete embryos or fetuses with focal anomalies. In this group we found 43 (9\%) cases of various clefts.

Seven (16 \%) cases were classified as R I, 14 (33\%) cases as R II, 15 (35 \%) as R III and 7 (16 \%) as R IV (Fig. 1).

In the $\mathrm{R}$ I group, unilateral cleft lip on the right side was the most prevalent (4 cases; $57 \%$ ) (Tab. 1; entries 2, 3, 4, 5). Associated disorders were found in 3 cases (43\%) - partial hydatiform mole without other congenital disorders in one case (entry 5) and multiple congenital disorders of organ systems in two cases (entries 3 and 6). Normal karyotype was only found in one case (14\%; entry 3), abnormal karyotype was found in three cases (43 \%; twice autosomal trisomy in entries 1 and 4 and once triploidy in entry 5), cultivation was unsuccessful in the last three cases (43\%; entries 2, 6, 7).

In R II group, bilateral CLP, which was once associated with transverse cleft of the face (7 \% of all R II cases) (Tab. 2; entry 8), was most prevalent (9 cases; $64 \%$; entries 1, 4-6, 8-12). Of these nine cases, one (7\%) had normal karyotype (entry 11) and

Tab. 1. Embryos and fetuses with R I.

\begin{tabular}{|c|c|c|c|c|}
\hline Entry & Type of cleft & Congenital anomalies & Fetal age & Karyotype \\
\hline 1 & R I/ bilat. & - & 42. - 43. day & 47, XY, +10 \\
\hline 2 & R I/ l. dx. & & 7. week & Unsuccessful cultivation \\
\hline 3 & R I/ l. dx. microform & Phocomelia l.sin., adactyly, defect of interventricular septum, SUA* & 17. week & $46, \mathrm{XX}$ \\
\hline 4 & R I/ l. dx. & & 6. -7 . week & 47, XY, +G \\
\hline 5 & R I/ l. dx. & Mola hydatidosa partialis & 40. day & $69, \mathrm{XXX}$ \\
\hline 6 & R I microform & Susp.hydrocephalus, susp. holoprosencephaly, cyclopia, polydactyly & 12. week & Unsuccessful cultivation \\
\hline 7 & R I/ l. sin. & - & 7.week & Unsuccessful cultivation \\
\hline
\end{tabular}


Tab. 2. Fetuses with R II.

\begin{tabular}{|c|c|c|c|c|}
\hline Entry & Type of cleft & Congenital anomalies & $\begin{array}{l}\text { Fetal age } \\
\text { (weeks) }\end{array}$ & Karyotype \\
\hline 1 & R II/ bilat. & & 12. & 46, XY, - D, +t (D. D) \\
\hline 2 & R II/ l. sin. & & 11. & $46, \mathrm{XY}$ \\
\hline 3 & R II/ l. dx. & $\begin{array}{l}\text { Anencephaly, agenesis of left eye, gastroschisis, thoracoschisis, ektopia } \\
\text { cordis, liver }\end{array}$ & 16. & $46, \mathrm{XX}$ \\
\hline 4 & R II/ bilat. & Miller - Dieker sy, omphalocele & 17. & 46, XY, der.(17),t(3;17)(p21;p13) \\
\hline 5 & R II/ bilat. & & 11. & Unsuccessful cultivation \\
\hline 6 & R II/ bilat. & Hydrocephaly, spina bifida, mola hydatidosa partialis & 17. & 69, XXY/ 70 XXY, +C (x) \\
\hline 7 & R II/ l. sin. & $\begin{array}{l}\text { Acrania, amniotic band } \\
\text { syndrome, clubfoot }\end{array}$ & 19. & $46, \mathrm{XY}$ \\
\hline 8 & $\begin{array}{l}\text { R II/ bilat. + } \\
\text { transverse facial cleft }\end{array}$ & Amniotic band syndrome syndactyly, clubfoot & 13. & Unsuccessful cultivation \\
\hline 9 & R II/ bilat. & Encephalocele, polydactyly, amniotic band Syndrome & 22. & Unsuccessful cultivation \\
\hline 10 & R II/ bilat. & Syndactyly of 2. 3.,4.rd finger & 11. & Unsuccessful cultivation \\
\hline$\overline{11}$ & R II/ bilat. & $\begin{array}{l}\text { Flattened nose, low-lying ears, syndactyly, absence of 3. rd toe, clubfoot } \\
\text { l.sin., pes valgus l. dx. }\end{array}$ & 22. & $46, \mathrm{XX}$ \\
\hline 12 & R II/ bilat. & Holoprosencephaly, mikroctalmia, pes valgus bilat. & 17. & Unsuccessful cultivation \\
\hline 13 & R II/ l. dx. & $\begin{array}{l}\text { CNS - dilatation of ventricular system, aplasia of vermis cerebelli, } \\
\text { hydrocephalus, polydactyly }\end{array}$ & 2. trimester & $47, X Y+13$ \\
\hline 14 & R II & Hygroma colli cysticum, cardiomegaly & 2. trimester & Unsuccessful cultivation \\
\hline
\end{tabular}

Tab. 3. Fetuses with R III.

\begin{tabular}{|c|c|c|c|c|}
\hline Entry & $\begin{array}{l}\text { Type } \\
\text { of cleft }\end{array}$ & Congenital anomalies & $\begin{array}{l}\text { Gestational } \\
\text { age (weeks) }\end{array}$ & Karyotype \\
\hline 1 & R III & - & 22. -23 . & $69, \mathrm{XXX}$ \\
\hline 2 & R III & Escobar sy, pterygium colli & 15. & 46, XX \\
\hline 3 & R III & Arnold- Chiari malformation, spina bifida, diafragmatic hernia, agenesis of kidneys, clubfoot & 16. & $46, \mathrm{XY}$ \\
\hline 4 & R III & Syndactyly, eventration of the abdominal viscera & 14. & $46, \mathrm{XX} / 69, \mathrm{XXX}$ \\
\hline 5 & R III & Anencephaly & 16. & $46, \mathrm{XX}$ \\
\hline 6 & R III & Susp. Encephalocele & 22. & Unsuccessful cultivation \\
\hline 7 & R III & Down syndrome & 17. & $47, X Y,+21$ \\
\hline 8 & R III & Spatulate fingers & 10. & Unsuccessful cultivation \\
\hline 9 & R III & Susp. hydrocephaly, syndactyly, SUA* & 13. & $69, \mathrm{XXX}$ \\
\hline 10 & R III & Acrania, anophtalmia l.dx., cryptophtalmia l. sin., hypoplastic nose low-lying ears, & 14. & Unsuccessful cultivation \\
\hline 11 & R III & Anencephaly, susp. encephalocele, clubfoot & 27. & Unsuccessful cultivation \\
\hline 12 & R III & Acrania, encefalomeningocele & 11. & $46, \mathrm{XY}$ \\
\hline$\overline{13}$ & R III & $\begin{array}{l}\text { Hypertelorism, dextrocardia, defect of interventricular septum, diaphragmatic hernia, } \\
\text { dilatation of renal pelvis bilat. }\end{array}$ & 17. & $47, \mathrm{XX}+\mathrm{C}(11)$ \\
\hline 14 & R III & Hygroma colli, hypoplastic nose, low-lying ears & 11. & Unsuccessful cultivation \\
\hline 15 & R III & Holoprosencephaly, encephalocele & II. trimester & $46, X Y$ \\
\hline
\end{tabular}

three (21\%) had an abnormal one - structural chromosomal aberrations twice (entries 1 and 4) and triploidy once (entry 6). The cultivation of five samples was unsuccessful (entries 5, 8-10, 12) and the determination of their karyotype was impossible. Four cases (29 \%) in R II group had normal karyotype (entries 2, 3, 7 and 11) - two cases had a unilateral CLP on the left side (entries 2 and 7), one on the right side (entry 3) and the already mentioned one had a bilateral CLP (entry 11).

Associated congenital disorders were found in 11 cases (79\%; entries 3-4, 6-14) - 3 with unilateral CLP (once on the left side in entry 7 and twice on the right side in entries 3 and 13), 7 with bilateral CLP (entries 4, 6, 8-12) and one where the laterality is unknown (entry 14).
In R III group, associated congenital defects were present in all but one case with triploidy (93 \%) (Tab. 3; entries 2-15). Cultivation was unsuccessful in five cases (33 \%, entries 6, 8, 10, 11 and 14 ), normal karyotype was found in five cases (33\%, entries $2,3,5,12,15)$ and abnormal also in five cases (33 \%; entries 1 , $4,7,9,13$ ) - twice triploidy (entries 1,9 ), once mosaic triploidy (entry 4) and once the trisomy of the 11th chromosome were found (entry 13).

In R IV group, median cleft lip and palate was the most prevalent (43\%) (Tab. 4, karyotyping was unsuccessful in two cases in entries 5 and 7 and once showed trisomy of the 13th chromosome in entry 2), followed by transverse cleft in 2 cases (29\%, entries 1 and 6, karyotyping was unsuccessful in both cases). 
401-406

Tab. 4. Fetuses with R IV.

\begin{tabular}{|c|c|c|c|c|}
\hline Entry & $\begin{array}{l}\text { Type } \\
\text { of cleft }\end{array}$ & Congenital anomalies & $\begin{array}{l}\text { Gestational } \\
\text { age (weeks) }\end{array}$ & Karyotype \\
\hline 1 & Transverse facial cleft & Auriculolabiale syndrome, R I & 10. & Unsuccessful cultivation \\
\hline 2 & Median cleft lip and palate & Omfalocele & 24. & $47, \mathrm{XY},+13$ \\
\hline 3 & Median cleft lip and nose & Polydactyly & 12. -13 . & $47, \mathrm{XY},+\mathrm{D}$ \\
\hline 4 & $\begin{array}{l}\text { Mikroform of cleft lower lip on } \\
\text { the right side }\end{array}$ & - & 17. & 46, XX \\
\hline 6 & Transverse facial cleft + R II/bilat. & $\begin{array}{l}\text { Amniotic band syndrome, hands syndactyly, aplasia of big toe, } \\
\text { clubfoot }\end{array}$ & 13. & Unsuccessful cultivation \\
\hline 7 & Median cleft lip and palate & $\begin{array}{l}\text { Hypertelorism, pterygium colli, flattened nose, polydactyly, } \\
\text { caudal regression }\end{array}$ & 15. & Unsuccessful cultivation \\
\hline
\end{tabular}

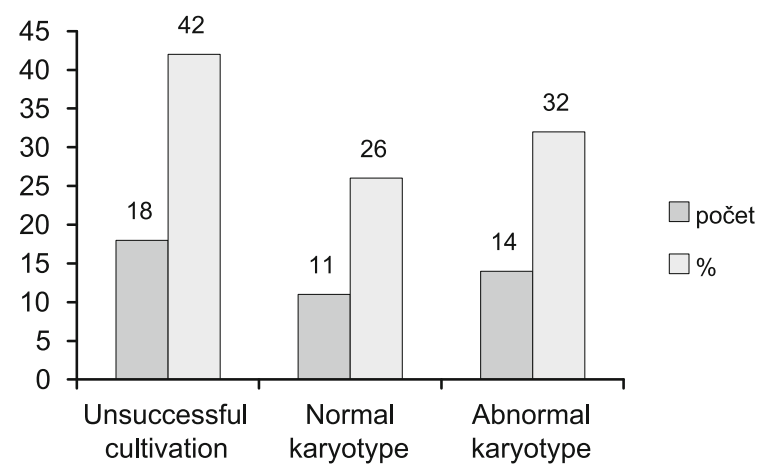

Fig. 2. Karyotypes in orofacial clefts.

One fetus had an R II bilateral cleft along with transverse cleft of the face (entry 6). Associated congenital disorders were found in 6 cases (86 \%, entries $1-3,5-7)$. In one case, median cleft of the lip and nose (trisomy D present, entry 3 ) and in another one microform of lower lip cleft with a normal karyotype were found (entry 4).

Cultivation was impossible in 18 of the 43 (42\%) cases and it was impossible to determine the karyotype. Eleven cases (26\%) of the cultivated material had normal karyotype and 14 cases (32\%) had a numerical or unbalanced structural chromosomal aberration (Fig. 2).

Tab. 5. Associated congenital anomalies in fetuses with orofacial clefts.

\begin{tabular}{lccc}
\hline Congenital anomalies & $\begin{array}{c}\text { Normal } \\
\text { karyotype }\end{array}$ & $\begin{array}{c}\text { Abnormal } \\
\text { karyotype }\end{array}$ & $\begin{array}{c}\text { Unsuccessful } \\
\text { cultivation }\end{array}$ \\
\hline NTD & 9 & 5 & 5 \\
\hline The face & 2 & 1 & 7 \\
\hline The neck & 1 & 0 & 3 \\
\hline The heart & 2 & 2 & 1 \\
\hline The abdominal wall & 2 & 4 & 1 \\
\hline GIT & 1 & 0 & 0 \\
\hline The urinary tract & 1 & 1 & 0 \\
\hline Skeletal dysplasias & 5 & 4 & 14 \\
\hline The umbilical cord & 1 & 1 & 0 \\
\hline $\begin{array}{l}\text { Other anomalies }- \\
\text { amniotic band syndrome }\end{array}$ & 1 & 0 & 2 \\
\hline
\end{tabular}

In this table, classification of congenital anomalies by Romero (16) was used.
Fetal facial clefts may be associated with various types of defects. Most common were anomalies of the skeleton (23), NTD (19) and anomalies of the abdominal wall (7) (Tab. 5). Associated congenital anomalies were found in all types of clefts, in accordance with literature (12). Thirty-three of the 43 cases (77\%) had multiple anomalies of organ systems, 9 had no associated anomalies (21\%) and one had no associated anomaly but it was a case of partial hydatiform mole (2\%).

Orofacial clefts were part of syndromes in 7 cases (16 \%) as follows: Miller-Dieker (1x), Escobar (1x), auriculo labial syndrome (1x) and amniotic band syndrome (4x).

Most anomalies were found in the R III group (93.3\%), R IV (85.7 \%), R II (78.6 \%) and least in R I group (42.9) (Fig. 3).

In cases of clefts with no associated congenital anomalies, 2 had a normal karyotype (22. $2 \%$ ), 4 had chromosomal aberrations (44. $4 \%$ ), and 3 samples were unsuccessfully cultivated (33. $3 \%$ ) (Fig. 4).

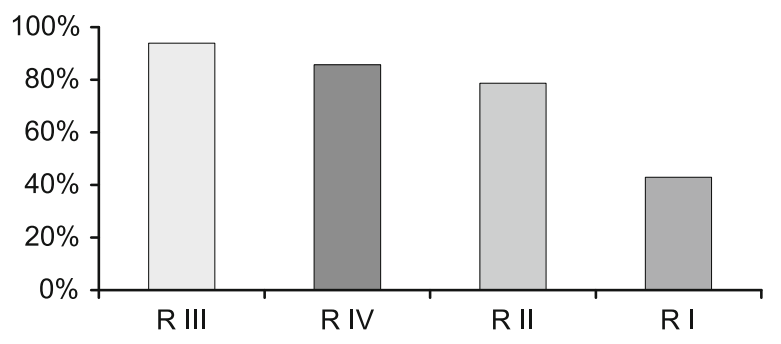

Fig. 3. Percentage of associated congenital anomalies in various types of orofacial clefts.

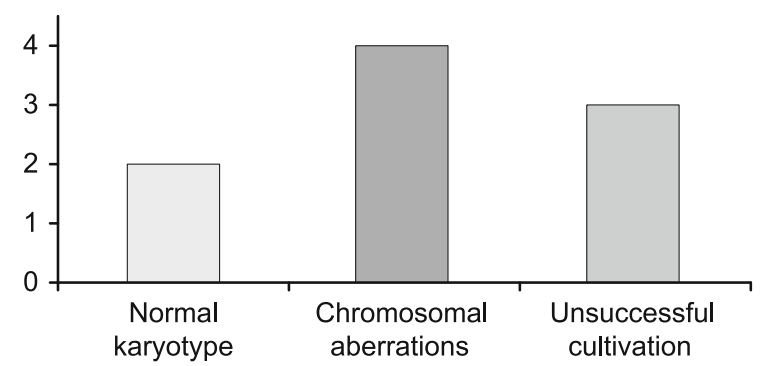

Fig. 4. Cytogenetic diagnosis in clefts without associated congenital anomalies. 


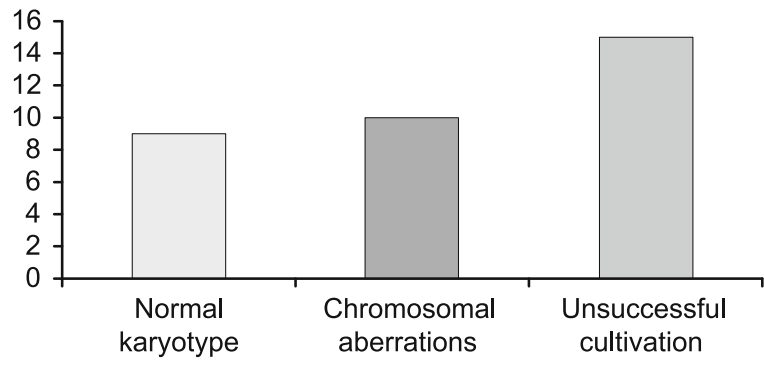

Fig.5.Cytogenetic diagnosis in clefts with associated congenital anomaly.

In cases of clefts with associated congenital anomalies, 9 had a normal karyotype (27 \%), 10 had chromosomal aberrations (29\%) and 15 samples were unsuccessfully cultivated (44\%) (Fig. 5).

\section{Discussion}

According to literature, clefts on the left side occur twice as often as those on the right side $(1,14)$. However, in our case pool, clefts on the right side (6 cases, 4 in R I and 2 in R II) were twice as likely ( 3 cases; 1 in R I and 2 in R II).

The boy-to-girl ratio represents approximate value of $2: 1$ (31, 10 ), in our case pool the obtained ratio is $1.3: 1$, in accordance with that of $1.46: 1$ found by Conway (4). In the R III group (isolated cleft palate), mostly girls are present according to Dar (5), Mai (9) or Barman (1). We obtained the same result (girl-to-boy ratio = $6: 4$ ).

Cleft palate was statistically associated with a greater number of minor defects and syndromic assignment (12). We diagnosed clefts of the lip and palate which were often associated with other congenital defects and chromosomal aberrations. Most common ones were those of skeleton (25) and NTD (21) which is consistent with the findings of Stoll (28) and Calzolari (3).

Taib (30) states, that approximately $35 \%$ of cleft lip and/or palate patients have another congenital anomaly and there are 200 syndromic associations. Perrotin (18) found associated congenital defects in 26 of 62 cases (42\%). However, we found associated congenital defects in 34 of 43 cases (79\%).

A higher occurrence of abnormal karyotype with associated congenital defects is reported in literature. For example, Perrotin (18) and Maarse (8) showed a higher frequency of chromosomal aberrations and associated congenital defects with CLP with isolated clefts.

Frequency of chromosomal aberrations with clefts with or without associated congenital defects are shown in Figures 4 and 5.

Isolated clefts were diagnosed in 9 of 43 cases (21\%).

The literature is not consistent when it comes to isolated clefts. For example, Nicolaides (15) reports only 9 out of 64 cases (13\%) while Nyberg (16) reports 23 out of 65 cases (35\%). Additionally, Perrotin (18) reports a high occurrence of isolated clefts, namely 36 out of 62 cases (58\%).

Our data did not show that isolated clefts were not associated with a higher risk of chromosomal aberrations (27). Chromosomal aberrations were found in $44.4 \%$ of our cases, not found in $22.2 \%$ of our cases and not determinable in $33.3 \%$ of the cases due to unsuccessful cultivation. We suspect however, that some of these could also contain a chromosomal aberration.

When compared to literature (0-13.3\%), higher percentage of chromosomal aberrations found in isolated clefts in our pool (44\%) can be explained by the age of the embryos and fetuses - usually between day 43 and week $12(20,23)$. It is nearly impossible to diagnose some associated congenital defects at such an early age.

In clefts with associated congenital disorders (79 \% in our pool) there is around one third of cases with an abnormal karyotype (29.4\%). The cultivation was unsuccessful in $44.1 \%$ of cases where the karyotype could not be determined. We again suspect, that chromosomal aberration could be present in some of these cases.

\section{Conclusion}

The possibly appliacable result of our work lies in the information for gynecologist or clinical geneticist. We can determine whether the pregnancy was viable, we can comment on the etiological factor which influenced the miscarriage and in case of congenital disorders we can make a prognosis for future pregnancy. However, we have to consider that clefts do not have equal etiology and the risk of recurrence is influenced by the number of family members with clefts, type and degree of the clefts and sex of the sufferers.

Orofacial clefts can be determined by the morphological investigation of the miscarried or aborted embryo or fetus. By performing a chromosomal analysis, it is possible to differentiate between clefts due to multiple factors and those due to a chromosomal syndrome. The determination of chromosomal sex in the embryos in which the genitals are not yet differentiated is of diagnostic and prognostic value.

The risk of recurrence of clefts with associated congenital disorders and chromosomal aberrations is dependent on the risk of chromosomal aberration recurrence. Its presence can be determined by prenatal genetic analysis.

The recurrence rate of clefts caused by multiple factors was reported from $0 \%$ to $60 \%$ (22), depending on the number of family members affected and the sex of the affected.

Because only 1-2 \% of clefts are identifiable by methods of molecular genetics according to literature, it is suspected that most of the clefts are due to multiple factors (25).

Progress in molecular biology significantly influences the diagnosis and therapy of orofacial clefts. Identification of candidate genes and elimination of outside factors in periconceptional time period (food, infectious diseases, medicines) can help in prenatal diagnostics and in prevention of cleft defects.

When recurrence is highly probable, early diagnosis with 3D sonography can be used.

\section{References}

1. Barman A, Dutta BC, Sarkar JK. Study of the distribution of different types of cleft lip and palate and associated anomalies. NJCA 2014; 3 (4): 203-208. 
401-406

2. Borges AD, Sa J, Hoshi R, Viene CS, Mariano LC, Veiga PD, Madrado AP, Machado RA, de Aquino SN, Messetti AC et al. Genetic risk factors for nonsyndromic cleft lip with or without cleft palate in a Brasilian population with high African ancestry. Amer J Med Genet Part A 2015; 167: 2344-2349.

3. Calzolari E, Pierini A, Astolfi G et al. Associated anomalies in multimalformed infants with cleft lip and palate: an epidemiologic study od nearly 6 million births in 23 EUROCAT registries. AM J Med Genet A 2007; 143 (6): 528-537.

4. Conway JC, Tasub PJ, Kling R, Oberoi K, Doucette J, Jabs EV. Ten-year experience of more tham 35 000orofacial clefts in Africa. BMC Pediat 2015; 15 (8): 328.

5. Dar P, Gross S. Craniofacial and neck anomalies. Clin Perinatol 2000; 27 (4): 813-837.

6. Fantel AG, Shepard TH, Vadheim-Roth $\mathrm{C}$ et al. Embryonic and Fetal phenotypes: Prevalence and other associated factors in a large study of spontaneous abortion. In: Porter SH, Hook EB (Ed). Human embryonic and fetal death. New York: Academic Press, 1980, 71-87.

7. Fujikura T, Froelich LA, Driscoll SG. A simplified anatomic classification of abortions. Amer J Obstet Gynec 1966; 95 (7): 902-905.

8. Maarse W, Rozendaal AM et al. A systematic review of associated structural and chromosomal defects in oral clefts: when is prenatal genetic analysis indicated? J Med Genet 2012; 49 (8): 490-498.

9. Mai CT, Cassell CH, Meyer RE. Birth defects data from populationbased birth defects surveillance programs in the United States, 2007 to 2011: highlighting orofacial clefts. Birth Defects Res A Clin Mol Teratol 2014; 10 (11): 895-904.

10. Matthews JLK, Oddone-Paolucci E, Harrop RA. The epidemiology of cleft lip and palate in Canada, 1998 to 2007. Cleft Palate Craniofac J 2015; 52: 417-424.

11. Millard DR. Cleft Craft. The Evolution of Its Surgery. I: The Unilateral Deformity (Vol 1). Philadelphia, PA: Lippincott Williams and Wilkins, 1976, 47.

12. Monlleo IL, de Barros AGR, Fontes Marshall IB, de Andrade AKM, de MBrito G, do Nascimento DLL, Gil-da-Silva-Lopes VL. Diagnostic implications of associated defects in patients with typical orofacial clefts. J Pediat 2015; 91: 485-492.

13. Moore KL. The developing human: clinically oriented embryology. Philadelphia - London - Toronto: W.B. Saunders Comp, 1973.

14. Nagase Y, Natsume N. Epidemiological Analysis of Cleft Lip and/ or Palate by Cleft Pattern. J Maxillofac Oral Surg 2010; 9 (4): 389-395.

15. Nicolaides KH, Salvesen DR et al. Fetal facial defects associated malformations and chromosomal abnormalities. Fetal Diagn Ther 1993; 8: 1-9.
16. Nyberg DA, Sickler GK et al. Fetal cleft lip with and without cleft palate: US classification and correlation with outcome. Radiology 1995; 195: $677-684$.

17. O'Rahily R, Muller F. Developmental Stages in Human Embryos. Washington, DC: Carnegie Institution of Washington, 1987.

18. Perrotin F, Poncheville LM. Chromosomal defects and associated malformations in fetal cleft lip with or without cleft palate. Eur J Obstet Gynecol Reprod Biol 2001; 99 (1): 19-24.

19. Reiter R, Brosch S, Ludeke M, Fischbein E, Rinckleb A, Haase S, Schwandt A, Pickhard A, Maier C, Hogei J et al. Do orofacial clefts represent different genetic entities? Cleft Palate Craniofac J 2015; 52: 115-120.

20. Rittler M, Cosentino V, Lopez-Camelo JS, Murray JC, Wehby G, Castilla EE. Associated anomalies among infants with oral clefts at birth and during a 1-year follow-up. Am J Med Genet A 2011; 155A: 1588-1596.

21. Romero R, Pilu G, Jeanti K et al. Prenatal Diagnosis of Congenital Anomalies. Norwalk; Connecticut/ San Mateo; Califomia: Appleton and Lange, 1988.

22. Ross RB, Johnston MC. Cleft Lip and Palate. Baltimore: Williams and Wilkins Comp, 1972, 98.

23. Rozendaal AM, Luijsterburg AJM, Ongkosuwito EM, Van den Boogaard MJH, De Vries E, Hovius SER, Vermeij-Keers C. Delayed diagnosis and under reporting of congenital anomalies associated with oral clefts in the Netherlands: a national validation study. J Plast Reconstr Aesthet Surg 2012; 65; 780-790.

24. Saltzman DH, Benacarraf BR, Frigoletto FD. Diagnosis and management of fetal facial clefts. Am J Obstet Gynec 1986; 155: 377-379.

25. Stanko P, Mračna J, Stebel A et al. Aktuálne o rážstepoch pery a podnebia. Pediatria Prax 2014; 15 (6): 232-233.

26. Stanko P, Stebel A, Vojtaššák J. Z etiológie, epidemiológie a vývoja terapie rázštepov pery a podnebia. Stomatolog 2012; 22 (2 - 3): 42-45.

27. Steinberg JP, Gosain AK. Thirty years of prenatal celft diagnosis: What have we learned? Plast Reconstr Surg 2015; 136: 550-557.

28. Stoll C, Alembik Y et al. Associated malformations in cases with oral clefts. Cleft Palate Craniofac J 2000; 37 (1): 41-47.

29. Streeter GL. Development horizons in human embryos. Embryology Reprint II. Washington, Carnegie Inst, 1951.

30. Taib BG, Taib AG, Swift AC, van Eeden S. Cleft lip and palate: diagnosis and managemet. Brit J Hosp Med 2015; 76: 584-591.

31. Tanaka SA, Mahabir RC et al. Updating the epidemiology of cleft lip with or without cleft palate. Plast Reconstr Surg 2012; 129 (3): 511-518.

Received November 11, 2015. Accepted December 21, 2015. 